CAHIERS

MONDES

ANCIENS

\section{Cahiers « Mondes anciens »}

Histoire et anthropologie des mondes anciens

$13 \mid 2020$

Qu'est-ce que faire école? Regards sur « l'école de

Paris »

\title{
Au-delà des Pyrénées
}

La gnosis desobediente de Nicole Loraux en los Estudios clásicos y de género hispanófonos

Au-delà des Pyrénées. La gnose indisciplinée de Nicole Loraux dans les études classiques hispanophones

Au-delà des Pyrénées. The undisciplined gnosis of Nicole Loraux in Classical Studies in the spanish speaking world

\section{Ana Iriarte}

\section{OpenEdition}

Journals

Edición electrónica

URL: http://journals.openedition.org/mondesanciens/2624

DOI: $10.4000 /$ mondesanciens. 2624

ISSN: 2107-0199

Editor

UMR 8210 Anthropologie et Histoire des Mondes Antiques

\section{Referencia electrónica}

Ana Iriarte, «Au-delà des Pyrénées », Cahiers « Mondes anciens » [En ligne], 13| 2020, mis en ligne le 10 juin 2020, consulté le 12 juin 2020. URL : http://journals.openedition.org/mondesanciens/2624 ; DOI : https://doi.org/10.4000/mondesanciens.2624

Este documento fue generado automáticamente el 12 junio 2020

\section{(c) (i) (9)}

Les Cahiers «Mondes Anciens » sont mis à disposition selon les termes de la licence Creative Commons Attribution - Pas d'Utilisation Commerciale - Pas de Modification 4.0 International. 


\title{
Au-delà des Pyrénées
}

\author{
La gnosis desobediente de Nicole Loraux en los Estudios clásicos y de \\ género hispanófonos
}

Au-delà des Pyrénées. La gnose indisciplinée de Nicole Loraux dans les études

classiques hispanophones

Au-delà des Pyrénées. The undisciplined gnosis of Nicole Loraux in Classical

Studies in the spanish speaking world

\section{Ana Iriarte}

1 Dejar constancia de la llamativa difusión experimentada en el universo hispanófono por las propuestas para el estudio del Mundo griego planteadas por los helenistas del "Centre Louis Gernet" y su entorno -incluso si nuestro objetivo enfoca, en última instancia, la obra de Nicole Loraux- nos sitúa, de entrada, ante una cantidad desmedida de autores, de grupos de investigación y citas bibliográficas. Además, para ser rigurosos en el intento, se debería incluso -o, sobre todo- rastrear los muchos ensayos nacidos como contra-tesis a planteamientos específicos de los autores relacionados con dicho Centre de recherches sur les sociétés anciennes. Pero este último ejercicio no sería fácil, pues las fuentes de inspiración no siempre quedaron reflejadas en adecuadas referencias, ni siquiera a pie de página.

2 Con todo, la tarea elegida es de tal empaque, que vamos a apoyarnos en las fechas de traducción al español de determinados ensayos parisinos, considerando dichas fechas como "indicios aprehensibles", "pistas significativas", del impacto que los helenistas en cuestión tuvieron en el ámbito hispanohablante. Somos conscientes, por supuesto, de que las traducciones no son "prueba irrefutable", no son la única medida del impacto al que nos referimos, tanto más cuanto que nuestro recorrido remonta a la España del Tardofranquismo (1969-1975) y de la Transición democrática (1975-1978), es decir, a aquellas "décadas prodigiosas" en las que la importación de libros editados en Francia era una práctica, oficiosa pero muy extendida, de supervivencia intelectual.

3 Por razones en gran parte relacionadas con la Historia contemporánea española, el helenismo predominante en los dos últimos tercios del siglo xx, fue más afecto a la tradición alemana que a la francesa, claramente delimitadas, incluso opuestas, en la 
época (Fernández Galiano 1969). Los especialistas más representativos del periodo franquista -de cuya inactividad política es claro indicio la desatención al fenómeno griego de la demokratía en sus trabajos- se formaron en la línea analítica promovida, en especial desde la Universidad de Gotinga, por Ulrich von Wilamowitz (1848-1931), como sabemos, gran erudito y tan riguroso en su trabajo filológico como embelesado por la perspectiva romántica que erige a la antigua Grecia en cuna del pensamiento eurocéntrico ${ }^{2}$. En el sentido de esta tendencia, resulta relevante, por ejemplo, el tipo de reconocimiento que le otorgan, todavía a finales de la década de los 60 , dos helenistas españoles de primera fila: Manuel Fernández Galiano y Francisco Rodríguez Adrados. Como botón de muestra, recordaremos el posicionamiento de este último en una conferencia pronunciada en la Universidad de Sevilla el 22 de marzo de 1968: "Nadie osaría recomendar -afirma Adrados a propósito de Nietzsche- sus audacias de filólogo diletante ni suscribiría sus exabruptos. Si se pudiera llegar a una síntesis entre lo mejor de él y lo mejor del gran Wilamowitz, se crearía la imagen del verdadero, del auténtico filólogo. Por más que, como a todos los ideales, tal vez le suceda a este lo mismo que temía Platón para el de su República: que se encuentran solamente en los cielos" (Rodríguez Adrados 1970, p.105).

4 En 1965, la editorial argentina Eudeba difunde la traducción al español de Los orígenes del pensamiento griego -sólo tres años después de su aparición en francés-, ensayo en el que Jean-Pierre Vernant propone un acercamiento a la antigua Grecia que se distancia de la perspectiva romántica y, explícitamente, de la visión del mundo griego recreada por la intelectualidad alemana: "La razón griega es la que permite actuar, de forma positiva, reflexiva, metódica, sobre los hombres en lugar de transformar la naturaleza. Tanto en sus limitaciones como en sus innovaciones, la razón griega es hija de la ciudad"3.

5 Esta perspectiva antropológica de Grecia, amplía notoriamente el escenario centrado en las célebres discrepancias entre Wilamowitz y su contemporáneo Nietzsche en el que, a menudo, se demoraban los debates del helenismo español instaurado. Mientras tanto, se va confeccionando, eso sí, la modesta colección de textos griegos de la Editorial Gredos, llamada a amortiguar el efecto devastador de la Guerra civil en la tradición cultural española y, por ende, en el estudio de las fuentes grecolatinas.

Inicialmente, esta colección de clásicos en castellano se alimenta, en buena medida, desde América Latina -Argentina, Chile y México, en particular- con el trabajo de los numerosos y conscientes profesores y pensadores que eligieron el exilio en ultramar ${ }^{4}$. A partir de los años 70 -con Carlos García Gual como asesor de la colección griega-, este eficaz ejercicio editorial derivará en la histórica Biblioteca Clásica de Gredos, cuyo intrépido objetivo de traducir al castellano "la totalidad" del legado escrito grecolatino -ya fueran textos mayores o menores- apunta claramente al ámbito universitario. Desde el inicio de la Transición española, la élite del profesorado especializado de enseñanza media y universitaria se vuelca en la realización de ediciones críticas de los textos clásicos, escrupulosamente precedidas de amplias y eruditas Introducciones, cuyas bibliografías recogen y acercan los más destacados logros de la tradición filológica y la crítica textual anglosajona.

7 Corrían aquellos tiempos de reparación del daño causado por la Guerra y la fase más feroz de la Dictadura, cuando se editaron las traducciones de dos autores cuya influencia en los jóvenes investigadores de los años 70 iba a ser tanto más acentuada cuanto que los programas oficiales de la universidad española demonizaban todavía los 
ensayos inspirados en el Materialismo histórico. Me refiero a Pierre Lévêque y su Aventure grecque de 1964, vertida al castellano por la editorial catalana Labor en 1968, así como a Moses I. Finley, introducido en el ámbito hispanohablante por la editorial mexicana FCE, la cual distribuyó con enorme éxito la traducción de The Ancient Economy en 1974, es decir al año siguiente de su edición en inglés.

El nexo de Pierre Vidal-Naquet con estas figuras internacionales del helenismo -con Lévêque en Clístenes el ateniense y, en el muy manejado manual Economía y sociedad en la antigua Grecia, con el colaborador de Finley, Michel Austin- convierten a Vidal-Naquet en el miembro del "Centre Louis Gernet" más reconocido entre los historiadores de Grecia, los cuales, en realidad, eran titulados en "Prehistoria e Historia antigua", hasta que el primer Gobierno socialista promulgó la Ley de Reforma Universitaria que, a partir de 1983, favoreció la especialización en Historia de Grecia.

En 1977 -año de la primera votación democrática tras la Dictadura y, por ende, de gran atención por parte de los pueblos españoles a las publicaciones centradas en las formas del autoritarismo y del Poder-, una antología de artículos sobre el tema Clases y luchas de clases en la Grecia antigua, editada en Akal por el historiador de la Antigüedad Alberto Prieto Arciniega, incluye dos reflexiones de Claude Mossé y Pierre Vidal-Naquet sobre la esclavitud en Grecia ${ }^{5}$, además de un capítulo consagrado por este último a "La obra de Moses I. Finley", que marcarán definitivamente la Historia social del Mundo griego elaborada en las décadas siguientes y, de forma emblemática, en el marco de GIREA, grupo de investigación sobre la esclavitud en la Antigüedad que integra en la "École de Besançon" a los más perspicaces historiadores hispanófonos de la Grecia antigua (Iriarte 2010).

La consagración de Pierre Vidal-Naquet como referente del helenismo en la universidad antifranquista -especialmente, de la mano de Carles Miralles y Jaume Portulas en la UB, de Domingo Plácido en la UCM y presidida, en la USC, por la dinámica creatividad de José Carlos Bermejo, alumno de Vidal-Naquet en el "Centre Louis Gernet"-, se plasma en la temprana traducción de Le chasseur noir. Formes de pensée et formes de société dans le monde grec, distribuida por la editorial catalana Península a partir de 1983.

11 En el prólogo de este estudio, recordémoslo, el erudito autor anota que no pasó en solitario el trance de ordenar sus ideas por escrito antes de anunciar con entusiasmo (1981, p.13) la inminente aparición de los dos primeros ensayos de su coadjutora Nicole Loraux: L'invention d'Athènes y Les enfants d'Athéna. Así pues, en el ámbito hispano, los libros-faro de Nicole Loraux se presentan de la mano de Vidal-Naquet. Poco después, el nombre de la historiadora resaltará en el selecto Comité de rédaction de Métis, revista presente desde su primer volumen (1986) en las bibliotecas especializadas en Arqueología, Filología clásica e Historia antigua, tanto en la Península como allende los mares, en institutos de investigación tan consolidados como el mexicano de "Filológicas" de la UNAM o el de "Historia Antigua y Medieval" argentino'.

En términos generales, hasta bien avanzada la década de los $80^{\prime}$ no puede hablarse de una verdadera eclosión de la denominada "École de Paris" en el helenismo hispanófono. De hecho, la traducción de Mythe et tragédie I (1972) no se edita hasta 1987 y hasta 1988 la de Les ruses de l'intelligence. La mètis des Grecs (1974). Si bien es cierto que en 1983 se había traducido el exitoso título de Marcel Detienne, Les jardins d'Adonis y que Dionysos à ciel ouvert aparece en Editorial Gedisa el mismo año de su publicación original, 1986. También es de reseñar la inmediatez con la que se vierte al castellano, en 1990, L'écriture d'Orphée, coincidiendo con los primeros pasos del grupo de especialistas en 
orfismo estimulado por Alberto Bernabé desde el CSIC y la Universidad Complutense de Madrid.

13 En lo referente a la concienzuda exploradora del Mundo griego que fue Nicole Loraux, dicha eclosión debuta en 1989, con el ensayo, tan breve como rotundo, Façons tragiques de tuer une femme (1985), editado en la distinguida colección "Literatura y Debate" de Visor (editorial cuyo prestigio, dicho sea como fútil anécdota, no aminoró el disgusto de la autora al recibir su texto en español bajo la efigie de un Apolo con aires de héroe de comic en la portada). Esta traducción, con pronta resonancia, resulta clave para explicar la acogida -circunspecta, cierto- del razonamiento propiciado por Nicole Loraux en los estudios hispanófonos de Historia de Grecia y -también con cierta reticencia- en la historiografía de corte feminista ${ }^{7}$. Dicha reticencia se sustenta en una razón de peso: la desconcertante "figura materna masculinizada en el momento de su deceso" detectada por nuestra aguda historiadora en su lectura de las fuentes trágicas, problematizaba el tradicional -y confortable- manejo de la categoría "mujer" como útil de primera necesidad para la Historia social practicada en la época. Y algo parecido podría afirmarse con respecto al ensayito Les mères en deuil (1990), traducido en 1995 por Ediciones Equis de Rosario (Argentina) y casi una década después, en 2004, por la madrileña Abada, dado que éste trabajo enfoca la -tan políticamente incorrecta- cólera latente en la figura femenina herida en su maternidad.

el umbral del Tercer milenio, desde el año 2000, la Historia de las mujeres en Occidente dirigida por Georges Duby y Michelle Perrot (1990), con la inmejorable distribución de Ediciones Taurus-Santillana, viene a ocupar un espacio preminente en las bibliotecas de las Facultades de Letras, propiciando una eficaz plataforma de lanzamiento, en el caso que nos ocupa, para "Qu'est-ce qu'une déesse"; artículo, muy citado, en el que Nicole Loraux desentraña la sutil "construcción griega de lo divino" mediante la que las diosas quedan relegadas al origen, mientras que la religión olímpica, una vez constituida, invita a centrarse en la estructura del Panteón; estructura que queda fijada, de una vez por todas, por los descendientes varones de Crono, con Zeus patér y patriarcal en cabeza.

En el ámbito hispanófono de los estudios griegos y feministas, este artículo sirve de iniciación en los planteamientos de un libro que, en realidad, Loraux había publicado con anterioridad: Les expériences de Tirésias. Le féminin et l'homme grec (1989), distribuido en castellano por la editorial porteña Biblos, en 2003, y, al año siguiente, por la catalana El Acantilado. Se trata, recordémoslo, de la obra en la que Nicole Loraux introduce el útil analítico de "opérateur féminin", el cual añade a la consideración de las "mujeres" como categoría -básica en la Historia social- el planteo de lo "femenino" como construcción helena de significativo alcance en la elaboración de aquella "identidad masculina" que tendió a apropiársela. Este excepcional repaso de las fuentes literarias mayores del legado griego desde el prisma de "lo femenino" como constructo heleno a examinar en permanencia en su interrelación con "lo masculino", sólo fue llamada a operar en el ejercicio de deconstrucción de los mitos patriarcales emprendido por contados helenistas y filósofas hispanoparlantes ${ }^{8}$.

Bien entrado ya el siglo xxI, el pensamiento de Nicole Loraux -su privilegiada "miramêtis"-, va penetrando al tiempo en las disciplinas de Historia Antigua y de Filología clásica con las traducciones de Né de la terre. Mythe et politique à Athènes (1996), Buenos Aires, Teoría y ensayo, 2007; La tragédie d'Athènes. La politique entre l'ombre et l'utopie (2005), Madrid, Akal, 2008 y La cité divisée. Critique de la politique (1997), Buenos Aires, 
Katz editores, 2008. Sólo tras la "buena acogida" de estos títulos - en la que también pueden incluirse las contra-tesis más o menos explícitas e incluso sañudas que inspiraron, como decíamos al principio -, en 2012, la competente editorial argentina Katz se arriesga con la traducción del libro por antonomasia de nuestra historiadora: L'invention d'Athènes. Histoire de l'oraison funèbre dans la cité classique, es decir, la Tesis de Estado que sostuvo en $1976^{9}$.

En cuanto al fomento, en el ámbito hispanófono, del eje reflexivo "masculino / femenino" -según el cual, recordémoslo de nuevo, las formulaciones griegas de la diferencia de sexo no se reducen a listados de oposiciones binarias, sino que denotan intercambio y amalgama-, aparecerá esencialmente mediatizado por la categoría analítica de "gender" (Franco y Iriarte 2009), tal y como queda fijada en el célebre artículo de la especialista en Historia contemporánea y en French Theory, Joan Wallace Scott, "Gender: A Useful Category of Historical Analysis" (1986). Un artículo tempranamente trasladado al castellano (1990), por mediación de Mary Nash ${ }^{10}$. En adelante, las filas del feminismo hispanófono vinculadas a la Historia de las mujeres se mostrarán especialmente proclives a emplear y difundir la noción de "género", categoría de manejo más cómodo, quizás, que los planteamientos analíticos de Loraux (quien fue poco adepta a los -ismos, todo hay que decirlo); si bien, podría decirse que la vocación de ambas aportaciones es trascender la categoría de "mujer" como instrumento de análisis histórico, priorizar el análisis de los géneros sexuales como constructo discursivo y alertar sobre el gran alcance de dicho análisis para desentrañar la Historia de las instituciones.

En este giro teórico -en buena medida derivado de los planteamientos de Jacques Derrida y de Michel Foucault-, reside la clave del desarrollo de los llamados estudios de género de finales del siglo $\mathrm{xx} y$, aunque ya no se recuerde explícitamente, de los de nuestro siglo XXI.

19 Ante este nuevo escenario, insistiremos en que la Historia antropológica "tramada" a mediados de la década de los 60' en el Centre de recherches comparées sur les sociétés anciennes -denominado "Centre Louis Gernet" a partir de 1984- implicaba ya una mirada crítica e interdisciplinar hacia esa misma "lógica binomial enraizada en la Grecia antigua" que el Abya Yala-denominación del continente americano anterior a la conquista española- o/y el Black Feminism más reciente critican desde la "interseccionalidad" y, significativamente, en el nombre de Foucault ${ }^{11}$. En lo que al minúsculo reducto de la Antigüedad griega se refiere, cuando aparecen títulos virales, como Black Athena, de Martin Gardiner Bernal (1987) -traducido con éxito desbordante "para España y América” por Crítica en 1993- la labor de deconstrucción de la célebre lógica binomial griega contaba ya con una significativa andadura.

Con el paso de las décadas, el nombre de Nicole Loraux se desdibuja, poco a poco, en las aleatorias bibliografías que "sustentan" la masiva producción historiográfica in transit por Internet. Sus hallazgos de esmerada pionera perduran. 


\section{BIBLIOGRAFÍA}

Adlbi Sibai S. (2016), La cárcel del feminismo. Hacia un pensamiento islámico decolonial, Madrid.

Bouque S. C. et alii ed. (1996), El género, la construcción cultural de la diferencia sexual, México D.F.

Fernández Galiano M. (1969), “Ulrich von Wilamowitz-Moellendorff y la Filología clásica de su tiempo", EClás 13-56, p.25-57.

Franco G. y Iriarte A. (2009), Nuevas rutas para Clio. El impacto de las teóricas francesas en la historiografía feminista española, Barcelona, p.11-20.

Iriarte A. (1999), “Los peligros del olvido como estrategia política”, Claves de razón práctica 93, p. 73-75.

- (2005), “Atenas imaginaria o la indivisibilidad como ideal político”, SHHA 23, p.161-175.

- (2006), “Descifrando enigmas con Nicole Loraux", Homenatge a Nicole Loraux, Ítaca 22, p.41-56.

- (2007a), "Pierre Vidal-Naquet y la Grecia marginal de los esclavos”, SHHA 25, p.35-44.

- (2007b), "Nicole Loraux y la teoría feminista", IV Congreso Internacional AUDEM: Los feminismos como herramientas de cambio social (II), Palma, p.251-256.

- (2007c), "Repensar la antigua Grecia con Nicole Loraux", en Alonso J., García C., y Mamolar I. ed., Stis ammoudies tou Omerou: homenaje a la profesora Olga Omatos, Bilbao, p.379-390.

- (2008), “El pensamiento de la división”, Prólogo a N. Loraux, La guerra civil en Atenas, Madrid, p. 5-28.

- (2009), "Nicole Loraux, la maternidad metafórica y la proximidad de lo distante", en Madres y maternidades. Construcciones culturales en la civilización clásica, Oviedo, p.31-47.

- (2010), "De mundo antiguo, contestatarios y tardofranquismo", en Dialéctica histórica y compromiso social. Homenaje a Domingo Plácido, Zaragoza, p.11-29.

- (2011), Historiografía y mundo griego, Bilbao.

- (2015), "Le miracle grec o la invisibilidad del esclavo", en Beltrán A., Sastre I. y Valdés M. ed., Los espacios de la esclavitud y de la dependencia desde la Antigüedad, Besançon, p.717-729.

Jufresa M. (2005), “Liens ibériques”, Les voies traversières de Nicole Loraux. Une helléniste à la croisée des sciences sociales, Espaces Temps 87-88, p.191-196.

Loraux, N. (1981), L'invention d'Athènes. Histoire de l'oraison funèbre dans la « cité classique ", ParisLa Haye-New York.

- (1981), Les enfants d'Athéna. Idées athéniennes sur la citoyenneté et la division des sexes, Paris.

- (1985), Façons tragiques de tuer une femme, Paris.

- (1989), Maneras trágicas de matar a una mujer, Madrid.

Rodríguez Adrados F. (1970), “Nietzsche y el concepto de la Filología Clásica”, Habis 1, p.87-105. Scott J. W. (1986), "El género: una categoría útil para el análisis histórico” en Amelang J. S. y Nash M. ed., Historia y género, Valencia, p.23-56.

Vernant J.-P. (1962), Les origines de la pensée grecque, Paris.

- (2007), CEuvres : religions, rationalités, politique, Paris. 
Vidal-Naquet P. (1981), Le chasseur noir. Formes de pensée et formes de société dans le monde grec,

Paris.

Zambrano M. (1998), Los intelectuales en el drama de España y escritos de la guerra civil, Madrid.

\section{NOTAS}

1. A la historia previa y posterior de esta institución me referí con detenimiento en Iriarte 2011, sobre todo, p.93-125.

2. Revisé la bibliografía sobre el tema en Iriarte 2015.

3. Vernant 1962, p.133. Cf., para este autor y su distanciamiento de los postulados de la filosofía alemana, Vernant 2007, p.2053-2054.

4. Testimonio de altura al respecto es la recopilación de textos de María Zambrano (1988), confeccionada por la propia autora en 1977.

5. Sobre cuya influencia me extendí en Iriarte 2007a.

6. En ellos destacan los profesores y responsables de grupos de investigación, David García (UNAM), cuyas ediciones de clásicos e investigación reflejan una fértil lectura de la obra de Vernant, Julián Gallego (CONICET), más vinculado con la de Vidal-Naquet y Elsa Rodríguez (UBACyT), inteligente receptora de las propuestas de Loraux.

7. Iriarte 2007b, 2009.

8. Así, Carles Miralles, Jaume Portulas, Maria Luisa Femenías, Maite Larrauri, Marina Picazo, Rosa Cid, Mercedes Madrid... Cf. Jufresa 2005.

9. A esta línea determinante de la obra de Loraux, dediqué trabajos como Iriarte 1999, 2005, 2006, 2007c, 2008, 2009.

10. Scott 1986. Cf. Bouque 1996.

11. Por elegir una obra, entre las muchas, de especial impacto en esta línea: Adlbi Sibai 2016.

\section{RESÚMENES}

Hasta mediados de los años $80^{\prime}$ no puede hablarse de una verdadera impronta de la denominada “École de Paris" en el ámbito universitario español, cuya rígida estructura traba el ejercicio interdisciplinar exigido por el estudio antropológico del Mundo griego. En lo que se refiere a Nicole Loraux, miembro destacada de este grupo de investigadores, su influencia se inicia con la traducción, en 1989, de Maneras trágicas de matar a una mujer, en la colección Literatura y Debate de Visor. Esta edición, muy bien distribuida, resulta clave para explicar la acogida de la obra de nuestra historiadora, con más premura en la especialidad de Filología clásica que en la de Historia antigua, y -no sin reticencias- en la heterogénea historiografía de corte feminista.

Jusqu'au milieu des années 1980 , on ne peut pas parler d'une empreinte marquante de l'« École de Paris » sur le champ universitaire espagnol, dont la structure rigide verrouille l'exercice 
interdisciplinaire exigé par l'étude anthropologique du monde grec. En ce qui concerne Nicole Loraux, membre remarquable de ce groupe de chercheurs, son influence commence à se faire sentir avec la traduction, en 1989, de Façons tragiques de tuer une femme, dans la collection Literatura y Debate de Visor. Cette édition, très bien diffusée, se révèle déterminante dans l'explication de la réception de l'œuvre de notre historienne, plus rapide chez les philologues classiques que chez les historiens antiquisants, et, non sans réticences, dans l'historiographie hétérogène de tendance féministe.

Until the mid-eighties the named "École de Paris" had not made a real mark in the Spanish university sphere, which, due to its rigid structure, hinders the interdisciplinary approach that the anthropologic investigation of the Greek world requires. As for Nicole Loraux, distinguished member of this group of scholars, her influence begins with the translation, in 1989, of Façons tragiques de tuer une femme (Maneras trágicas de matar a una mujer) in Visor's collection Literatura y Debate. This edition, widely distributed, is key to explain the reception of our historian's work, more in the Classical Philology specialty than in the Ancient History field, and - not without reluctance - in the heterogeneous historiography of a feminist approach.

\section{ÍNDICE}

Mots-clés: réception, Nicole Loraux, Espagne

Palabras claves: recepción, Nicole Loraux, España

\section{AUTOR}

\section{ANA IRIARTE}

Universidad del País Vasco (Vitoria, Espagne) 